\title{
Welcome letter from the president of Society of Korean Robot Gynecologic Surgery
}

\author{
Mee-Ran Kim \\ Department of Obstetrics and Gynecology, College of Medicine, The Catholic University of Korea, Seoul, Korea
}

Gynecologic Robotic Surgery (GRS) is the official journal of the Society of Korean Robotic Gynecologic Surgery (SKRGS), and it has been an honor to be serving as the 2nd president of the SKRGS since October 2019. As I write this letter with great excitement, I hope to reach gynecologic surgeons not only in Korea but also throughout Asia and the world and facilitate a wider dialogue among us.

With the inaugural issue of June 2019, we now follow its success with the second volume. I express my deepest gratitude to those who have made this possible, including the Editor-in-Chief Chi-Heum Cho, Deputy Editor Keun Ho Lee, and Editorial Board members. Thank you for your commitment and contribution to GRS, and as president, I will do my best to support the journal's vision.

Globally, we are being challenged by a pandemic and its unprecedented effects, and as members of the medical field, we are responding and adapting from our respective places. We may be non-connected, but the challenges have united us in our mission. We aspire to build a community to open conversations and for the continued research, education, and development of gynecologic robotic surgery.

This is the first publication that focuses on gynecologic robotic surgery at its core, and we trust it will provide a significant academic contribution to the subject. I am excited to be a part of this journey of research and exploration, and l encourage you to join us.

- Received: September 7, 2020 • Accepted: September 12, 2020

- Correspondening author: Mee-Ran Kim

Division of Reproductive Endocrinology, Department of Obstetrics and Gynecology, College of Medicine, The Catholic University of Korea, 222 Banpo-daero, Seocho-gu, Seoul 06591, Korea

E-mail:mrkim@catholic.ac.kr

This is an Open Access article distributed under the terms of the Creative Commons Attribution Non-Commercial License (http://creativecommons.org/ licenses/by-nc/4.0) which permits unrestricted non-commercial use, distribution, and reproduction in any medium, provided the original work is properly cited. 